\title{
Ring-Opening Copolymerization of Trimethylene Carbonate and D,L-Lactide by Rare Earth Chloride
}

\author{
Qiaohong Huang, Zhiquan Shen, ${ }^{\dagger}$ Yifeng Zhang, Youqing Shen, \\ Lianfang SHEN, ${ }^{*}$ and Hanzhen YUAN* \\ Department of Polymer Science and Engineering, Zhejiang University, \\ Hangzhou 310027, People's Republic of China \\ * State Key Laboratory of Magnetic Resonance and Atomic and Molecular Physics, \\ Wuhan Institute of Physics, Academia Sinica, \\ Wuhan 430071, People's Republic of China
}

(Received April 22, 1997)

\begin{abstract}
Bulk copolymerization of trimethylene carbonate (TMC) and D,L-lactide (D,L-LA) was conducted at $80^{\circ} \mathrm{C}$ using rare earth chloride as catalyst. The copolymerization reaction showed an induction period. The effects of reaction time and temperature were examined. The polymerization activity of various rare earth chlorides was in the order: $\mathrm{LaCl}_{3}>\mathrm{YCl}_{3}$, $\mathrm{PrCl}_{3}>\mathrm{NdCl}_{3} \gg \mathrm{DyCl}_{3}$. The copolymer was characterized by ${ }^{1} \mathrm{H}$ NMR. The reactivity ratios of TMC and D,L-LA were determined by the Fineman-Ross and Kelen-Tüdös methods.

KEY WORDS Ring-Opening Copolymerization / Trimethylene Carbonate / D,L-Lactide / Rare Earth

Chloride /
\end{abstract}

Biodegradable materials are of great interest due to their versatile applications. Intensive research is being conducted in this field. Now the main target is to prepare biodegradable polymers with specified properties. Copolymerization can attain such an object and provide new materials.

Polylactide (PLA) is an important biodegradable material. In order to control its biodegradation rate and mechanical properties, D, L-lactide (D,L-LA) and L-lactide (L-LA) have been copolymerized with other monomers such as $\varepsilon$-caprolactone (CL), ethylene oxide, ${ }^{1,2}$ etc. The six member cyclic aliphatic carbonate is a relatively new biodegradable monomer. ${ }^{3}$ Copolymerization of $\mathrm{D}, \mathrm{L}-\mathrm{LA}$ and trimethylene carbonate (TMC) is expected to lead to new biodegradable material.

Our group has successfully developed the rare earth catalysts for the polymerization and copolymerization of a series of cyclic monomers, including epoxides, alkylene sulfides, lactones, etc. ${ }^{4-6}$ Recently, we found that the rare earth halides are good catalysts for polymerization of CL, TMC and copolymerization of CL and TMC. ${ }^{7-9}$ This article reports the copolymerization of D,L-LA and TMC in bulk using rare earth chloride as catalyst. The structure of the copolymer was characterized by GPC and NMR and the reactivity ratios of TMC and D, L-LA were determined.

\section{EXPERIMENTAL}

\section{Materials}

TMC was synthesized according to ref 10 , then recrystallized from dried ethyl ether for three times. D,L-LA was prepared from D,L-lactic acid as described in ref 11 and recrystallized three times from dried ethyl acetate.

Rare earth chlorides: lanthanum chloride $\left(\mathrm{LaCl}_{3}\right)$, yttrium chloride $\left(\mathrm{YCl}_{3}\right)$, praseodymium chloride $\left(\mathrm{PrCl}_{3}\right)$,

\footnotetext{
† To whom correspondence should be addressed.
}

neodymium chloride $\left(\mathrm{NdCl}_{3}\right)$, and dysprosium chloride $\left(\mathrm{DyCl}_{3}\right)$ were prepared from their oxides. ${ }^{12} \mathrm{~A} \gamma$ butyrolactone solution of rare earth chloride $(0.15 \mathrm{M})$ was used as the polymerization catalyst.

Methylene chloride and methanol were of chemical grade and used as received. $\gamma$-Butyrolactone was refluxed over calcium hydride and distilled under reduced pressure.

\section{Polymerization}

All copolymerizations were carried out under dry nitrogen. Afterwards, the resulting copolymers were dissolved in methylene chloride and precipitated by methanol containing $5 \% \mathrm{HCl}$ and washed with methanol several times, and then dried at $40^{\circ} \mathrm{C}$ in vacuo for $24 \mathrm{~h}$.

\section{Measurements}

${ }^{1} \mathrm{H}$ and ${ }^{13} \mathrm{C}$ NMR spectra were obtained on a Bruker400 spectrometer in $\mathrm{CDCl}_{3}$ at room temperature with tetramethylsilane (TMS) as internal reference.

The molecular weight (MW) and molecular weight distribution (MWD) of the copolymer were determined by a Waters $150 \mathrm{c}$ GPC at $25^{\circ} \mathrm{C}$ and calibrated with polystyrene standards. Tetrahydrofuran (THF) was used as eluent at a flow rate of $1 \mathrm{ml} \mathrm{min}^{-1}$.

Intrinsic viscosity of copolymer was determined in methylene chloride at $25^{\circ} \mathrm{C}$ by an Ubbelohde viscometer.

\section{RESULTS AND DISCUSSION}

\section{Characteristics of Copolymerization}

Rare earth halides polymerize TMC at a temperature slightly higher than the melting point, which is about $50^{\circ} \mathrm{C}$. $^{7}$ However, D, L-LA can not polymerize in bulk or in solution under $80^{\circ} \mathrm{C}$ by rare earth chloride. A mixture of TMC and D,L-LA melts at $80^{\circ} \mathrm{C}$. Therefore, the copolymerization was generally carried out at $80^{\circ} \mathrm{C}$. 


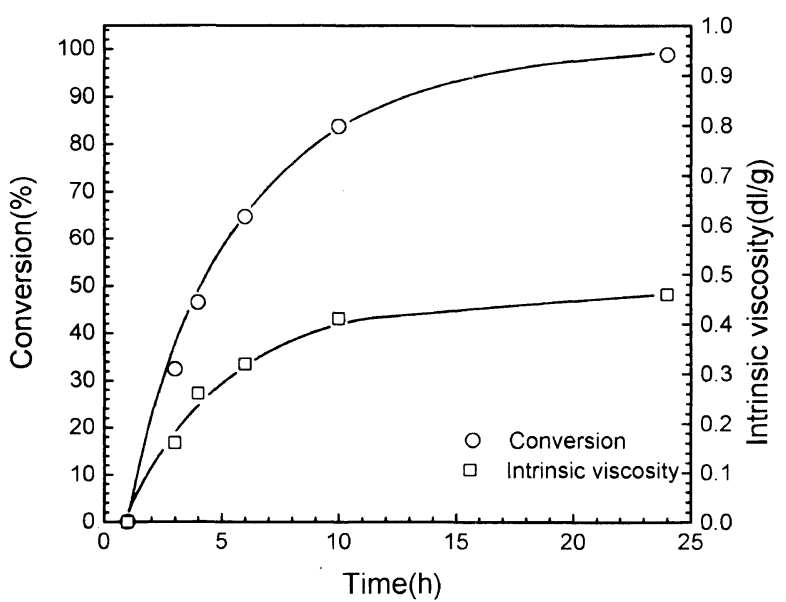

Figure 1. Conversion and intrinsic viscosity of a copolymer as a function of copolymerization time. Temperature, $80^{\circ} \mathrm{C}$; catalyst, lanthanum chloride; $[\mathrm{M}] /[\mathrm{C}]=500 ; \mathrm{TMC} / \mathrm{D}, \mathrm{L}-\mathrm{LA}=50 / 50$ (molar ratio in feed).

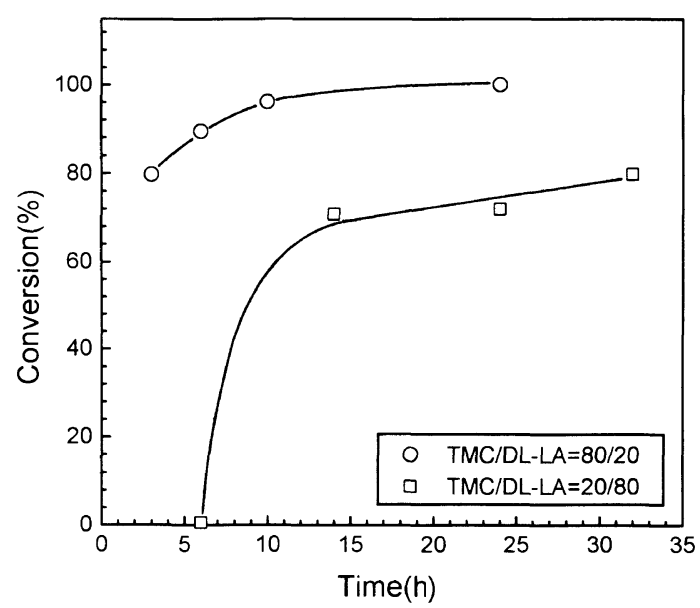

Figure 2. Conversion of a copolymer as a function of copolymerization time. Effects of various comonomer ratios. Polymerization conditions as Figure 1.

The copolymerization characteristics was shown in Figures 1 and 2. Figure 1 depicts the conversion and intrinsic viscosity of the copolymer as a function of polymerization time. From the data, it can be seen that both conversion and intrinsic viscosity of the copolymer increase with the elongation of polymerization time and there is an induction period of the polymerization, which decreases with increasing TMC in the feed (Figure 2).

Temperature affects polymerization. As indicated in Table I, the higher the temperature, the faster the copolymerization rate. A mixture of TMC and D,L-LA only partially melts at $60^{\circ} \mathrm{C}$, and this may be the reason for a low conversion. At $150^{\circ} \mathrm{C}$ with a long polymerization duration $(8 \mathrm{~h})$, the conversion and $\mathrm{MW}$ of copolymer were dropped, possibly due to transesterification inducing degradation of macromolecular chain and formation of oligomer, ${ }^{15}$ which is proved by GPC in Figure 3. When the copolymerization took place at $120^{\circ} \mathrm{C}$, the conversion attained $94 \%$ and copolymer with MW $2.75 \times 10^{4}$ and MWD 1.52 was prepared (Table I, No. 4).

The catalytic activity of various rare earth chlorides for copolymerization followed the order: $\mathrm{LaCl}_{3}>\mathrm{YCl}_{3}$,
Table I. Effects of temperature on copolymerization of TMC and D,L-LA

\begin{tabular}{lrrrrrr}
\hline \multicolumn{1}{c}{ No. } & 1 & 2 & 3 & 4 & 5 & 6 \\
\hline$T /{ }^{\circ} \mathrm{C}$ & 60 & 80 & 100 & 120 & 120 & 150 \\
$t / \mathrm{h}$ & 10 & 10 & 10 & 1 & 8 & 8 \\
$\mathrm{Conv} / \%$ & 2 & 84 & 94 & 94 & 90 & 85 \\
{$[\eta]^{\mathrm{a}}$} & - & 0.41 & 0.44 & 0.44 & 0.41 & 0.29 \\
$\mathrm{MW}^{\mathrm{b}}\left(\times 10^{3}\right)$ & - & 26.8 & - & 27.5 & 28.6 & 12.3 \\
$\mathrm{MWD}^{\mathrm{c}}$ & - & 1.49 & - & 1.52 & 1.50 & 1.44 \\
\hline
\end{tabular}

Catalyst, $\quad \mathrm{LaCl}_{3} ; \quad[\mathrm{M}] /[\mathrm{C}]=500 ; \quad \mathrm{TMC} / \mathrm{D}, \mathrm{L}-\mathrm{LA}=50: 50$ (molar ratio in feed). ${ }^{a}$ Intrinsic viscosity at $25^{\circ} \mathrm{C}$ in $\mathrm{CH}_{2} \mathrm{Cl}_{2}$. ${ }^{\mathrm{b}}$ Weight average $\mathrm{MW}, \mathrm{GPC}$ data at $25^{\circ} \mathrm{C}$ in THF. ${ }^{\circ} \mathrm{GPC}$ data at $25^{\circ} \mathrm{C}$ in THF.

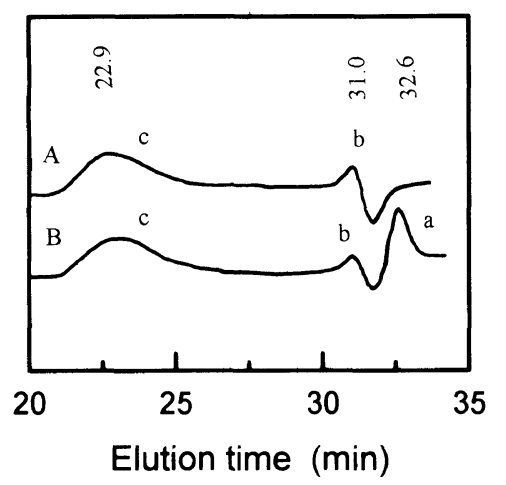

Figure 3. GPC curves of (A) reaction sample of TMC and D,L-LA after $8 \mathrm{~h}$ at $150^{\circ} \mathrm{C}$, (B) (A) plus comonomer mixture of 50:50 (molar ratio) TMC and D,L-LA. a, peak of monomer; b, peak of oligomer; c, peak of polymer.

Table II. Comparison of various rare earth compounds on polymerization activity

\begin{tabular}{lccccc}
\hline No. & 1 & 2 & 3 & 4 & 5 \\
\hline Catalysts & $\mathrm{YCl}_{3}$ & $\mathrm{LaCl}_{3}$ & $\mathrm{PrCl}_{3}$ & $\mathrm{NdCl}_{3}$ & $\mathrm{DyCl}_{3}$ \\
Conv $/ \%$ & 70 & 84 & 69 & 52 & 2 \\
\hline
\end{tabular}

Conditions, $80^{\circ} \mathrm{C} ;[\mathrm{M}] /[\mathrm{C}]=500 ; \mathrm{TMC} / \mathrm{D}, \mathrm{L}-\mathrm{LA}=50: 50$ (molar ratio in feed), $10 \mathrm{~h}$.

$\mathrm{PrCl}_{3}>\mathrm{NdCl}_{3} \gg \mathrm{DyCl}_{3}$ as shown in Table II. $\mathrm{LaCl}_{3}$, showing the highest activity, is a good catalyst, because it is cheap, stable and easy to prepare. $\mathrm{DyCl}_{3}$ is much less active than others. The composition of the copolymers prepared by the above rare earth chlorides was the same as that produced by lanthanum chloride.

\section{NMR of Copolymer}

${ }^{1} \mathrm{H}$ NMR spectra of the resulting copolymer, which justifies the structure of TMC and D,L-LA copolymer, are shown in Figures 4 and 5.

\section{Reactivity Ratios of Comonomers}

The Finemen-Ross and Kelen-Tüdös methods, ${ }^{13,14}$ both based on the Mayor-Lewis equation, were used to determine the reactivity ratios $r_{1}$ and $r_{2}$. Copolymerization was carried out with $\mathrm{LaCl}_{3}$ at $80^{\circ} \mathrm{C}$ in bulk. The composition of the copolymer was determined from ${ }^{1} \mathrm{H}$ NMR spectra using distinct peaks of $\delta=5.04$ (PLA) and $\delta=4.21$ (poly(trimethylene)carbonate) (PTMC).

The data by Fineman-Ross method (eq 1) are shown in Table III. The reactivity ratios of $r_{1}$ (TMC) and $r_{2}$ 

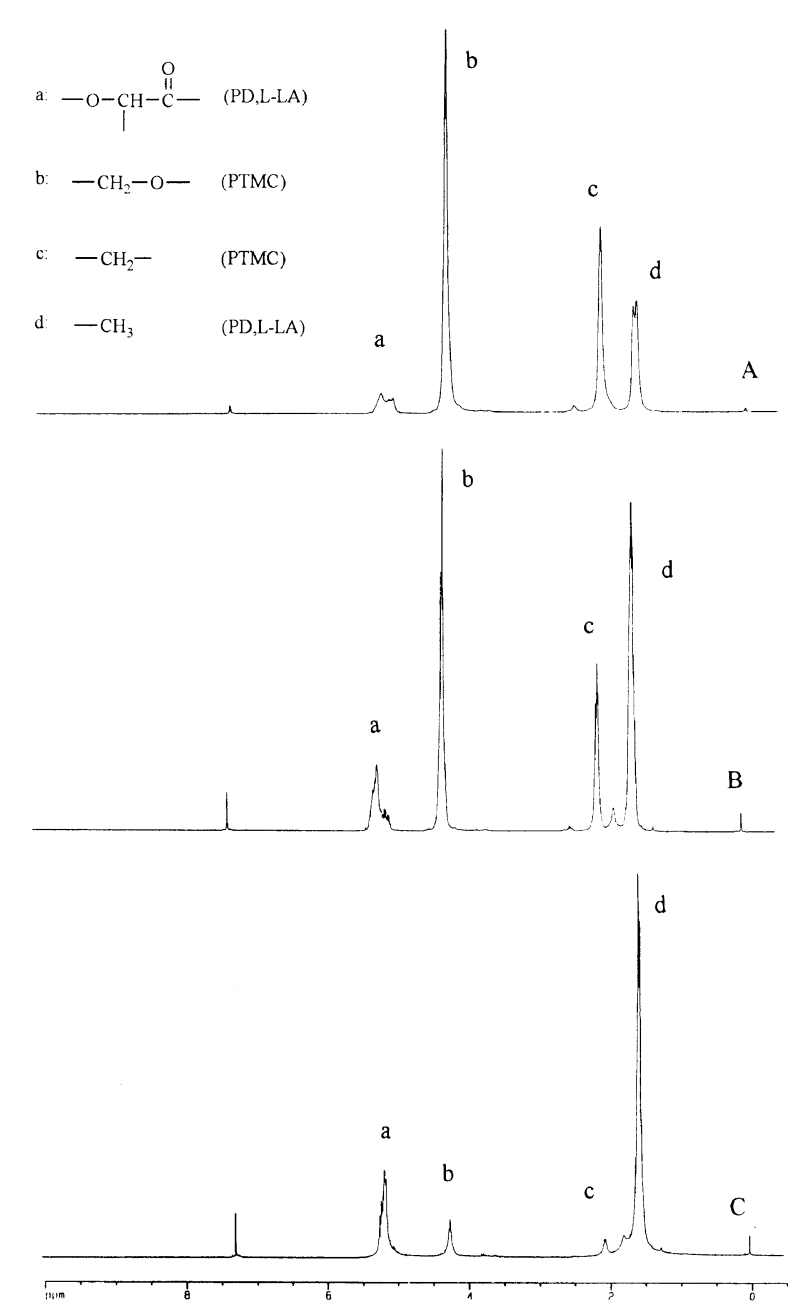

Figure 4. ${ }^{1} \mathrm{H}$ NMR of poly(TMC-co-D,L-LA). A, TMC/D,L-LA= $80 / 20$ (molar ratio in feed); $\mathrm{B}, \mathrm{TMC} / \mathrm{D}, \mathrm{L}-\mathrm{LA}=50 / 50$ (molar ratio in feed); $C, T M C / D, L-L A=20 / 80$ (molar ratio in feed).

Table III. Determination of $r_{1}$ and $r_{2}$

\begin{tabular}{ccrrrr} 
No. & 1 & 2 & \multicolumn{1}{c}{3} & \multicolumn{1}{c}{4} & \multicolumn{1}{c}{5} \\
\hline$x^{\mathrm{a}}$ & 4.302 & 3.116 & 1.587 & 0.960 & 0.644 \\
$y^{\mathrm{b}}$ & 0.389 & 0.260 & 0.131 & 0.0705 & 0.0425 \\
$G$ & -6.757 & -8.869 & -10.528 & -12.657 & -14.509 \\
$F$ & 47.576 & 37.344 & 19.226 & 13.072 & 9.758 \\
$\eta$ & -0.0978 & -0.151 & -0.258 & -0.366 & -0.463 \\
$\xi$ & 0.688 & 0.634 & 0.472 & 0.378 & 0.312 \\
\hline
\end{tabular}

Catalyst, $\mathrm{LaCl}_{3}$; temperature, $80^{\circ} \mathrm{C} ; \alpha=21.546$. ${ }^{\text {a }}$ Molar ratio in the feed. ${ }^{b}$ Molar ratio of monomer units in the copolymer, NMR data. Refer to text for the codes of $G, F, \eta$, and $\xi$.

(D,L-LA) were 0.19 and 15.4 , respectively with a correlation coefficient of 0.962 .

$$
G=r_{1} \cdot F-r_{2}
$$

where

$$
G=\frac{x(y-1)}{y} \quad F=\frac{x^{2}}{y} \quad x=\frac{m_{1}}{m_{2}} \quad y=\frac{d m_{1}}{d m_{2}}
$$

$m_{1}$ : mole fraction of TMC in feed

$m_{2}$ : mole fraction of D,L-LA in feed

$d m_{1}$ : mole fraction of TMC in polymer

$d m_{2}$ : mole fraction of D,L-LA in polymer

$r_{1}:$ reactivity ratio of $\mathrm{TMC}$

$r_{2}$ : reactivity ratio of $\mathrm{D}, \mathrm{L}-\mathrm{LA}$

Kelen-Tüdös method (eq 2) was used for comparison. The same $r_{1}(0.19)$ and $r_{2}(15.5)$ were obtained (Table III). The correlation coefficient was 0.989 by this method.

$$
\eta=\left(r_{1}+\frac{r_{2}}{\alpha}\right) \xi-\frac{r_{2}}{\alpha}
$$

where

$$
\eta=\frac{G}{\alpha+F} \quad \xi=\frac{F}{\alpha+F} \quad \alpha=\sqrt{F_{\min } F_{\max }}
$$

$\mathrm{D}, \mathrm{L}-\mathrm{LA}$ is thus more active than TMC under the present conditions and block-like copolymer was prepared. The copolymerization mechanism is now under investigation.

Acknowledgments. We gratefully acknowledge the financial support of Zhejiang University K. P. Chao's High Technology Development Foundation; Zhejiang Provincial Commision of Science and Technology and The State Education Commission.

\section{REFERENCES}

1. C. Jacobs, $\mathrm{Ph}$. Dubois, R. Jerome, and $\mathrm{Ph}$. Teyssie, Macromolecules, 24, 3027 (1991).

2. P. Vanhoorne, Ph. Dubois, R. Jerome, and Ph. Teyssie, Macromolecules, 25, 37 (1992).

3. D. J. Brunelle, in "Ring-Opening Polymerization: Mechanisms, Catalysts, Structure, Utility," D. J. Brunelle, Ed., Hanser, Munich, Vienna, New York, Barcelona, 1993, p 309.

4. J. Wu and Z. Q. Shen, J. Polym. Sci., Part A, Polym. Chem. Ed., 28, 1995 (1990).

5. Z. Q. Shen, X. H. Chen, Y. Q. Shen, and Y. F. Zhang, J. Polym. Sci., Part A, Polym. Chem. Ed., 32, 597 (1994).

6. X. H. Chen, Z. Q. Shen, and Y. F. Zhang, Macromolecules, 24, 5305 (1991).

7. Y. Q. Shen, Z. Q. Shen, Y. F. Zhang, and Q. H. Huang, J. Polym. Sci., Part A, Polym. Chem. Ed., 35, 1339 (1997).

8. Y. Q. Shen, Z. Q. Shen, Y. F. Zhang, and Q. H. Huang, J. Appl. Polym. Sci., 2132 (1997).

9. Y. Q. Shen, Z. Q. Shen, J. L. Shen, Y. F. Zhang, and K. M. Yao, Macromolecules, 29, 3441 (1996).

10. W. H. Carothers and F. J. Van Naha, J. Am. Chem. Soc., 52, 314 (1930).

11. R. K. Kulkarni, E. G. Moore et al., J. Biomed Mater. Res., 5, 169 (1971).

12. M. D. Taylor and C. P. Carter, J. Inorg. Chem., 24 387 (1962).

13. T. Kelen and F. Tüdös, J. Macromol. Sci., Chem., A9, 1 (1975).

14. F. Tüdös, T. Kelen, T. Foldes-Berezsnich, and B. Turcsanyi, J. Macromol. Sci., Chem., A10, 1513 (1976).

15. H. R. Kricheldorf, Martin Berl, and Nice Scharmagl, Macromolecules, 21, 286 (1988). 